\title{
Newer aspects of micronutrients in chronic disease: copper
}

\author{
BY J. J. STRAIN \\ Human Nutrition Research Group, University of Ulster, Coleraine BT52 1SA, Northern Ireland
}

The proliferation of citations on $\mathrm{Cu}$ appearing on computer databases such as MEDLINE 'Dialog Service' indicate the increasing interest in the metabolism of this micronutrient in chronic disease processes. A review based on a presentation given at a Nutrition Society meeting cannot hope to cover all aspects of the involvement of $\mathrm{Cu}$ in chronic disease. One pathological process, however, associated with a number of chronic diseases, is oxidative damage (Strain et al. 1991). The current review attempts to define the role of $\mathrm{Cu}$ in oxidative damage and then indicate how these roles might relate to mechanisms involved in ischaemic heart disease (IHD), the chronic disease which is the major cause of premature death in most Western societies. At the same time it should also become obvious that the versatility of $\mathrm{Cu}$ in metabolism gives this micronutrient potential roles which extend beyond those associated with pro-oxidant or antioxidant properties.

\section{COPPER AS A PRO-OXIDANT}

The most important reactants in free-radical biochemistry in aerobic organisms are reduced derivatives of oxygen (Cheeseman \& Slater, 1993) categorized as reactive oxygen species (ROS). ROS are toxic as they can oxidize biomolecules leading to cell death and tissue injury (Fig. 1). Of these the hydroxyl radical is the most reactive and is generally the ROS favoured as the initiator of free-radical-mediated chain reactions involving biomolecules. Although all the major classes of biomolecules can be attacked by ROS, lipids, especially polyunsaturated fatty acids in cell membranes, are probably the most susceptible to initiation and propagation of chain reactions. The breakdown of lipid hydroperoxides formed in these chain reactions to yield lipid peroxyl and alkoxyl radicals and other toxic products can be catalysed by transition $\left(\mathrm{Fe}^{2+}\right.$ and $\left.\mathrm{Cu}^{+}\right)$metal ions. Moreover, these transition metal ions are important catalysts for the initial generation of the hydroxyl radical in in vitro systems. There is currently much debate, however, on the ROS that initiate lipid peroxidation and the precise involvement of transition metals in these systems (Halliwell \& Chirico, 1993).

The participation of transition metal ions in oxidative modification of low-density lipoprotein (LDL), suggested to play a causal role in atherosclerosis (Steinberg et al. 1989), has received much interest. There is a strict requirement for transition metal ions before LDL oxidation can occur in vitro and $\mathrm{Cu}^{2+}$ has been recognized as the most effective catalyst (Esterbauer et al. 1992). Fe salts can also oxidatively modify LDL but they require a source of superoxide to reduce $\mathrm{Fe}^{3+}$ to $\mathrm{Fe}^{2+}$, whereas $\mathrm{Cu}^{2+}$-mediated oxidation of LDL can occur without superoxide production and is also independent of $\mathrm{H}_{2} \mathrm{O}_{2}$ and aqueous hydroxyl radical (Lynch \& Frei, 1993). Adding $\mathrm{CuSO}_{4}$ to cell culture media or phosphate-buffered saline $(9 \mathrm{~g} \mathrm{NaCl} / 1)$ is the usual method for preparing oxidized LDL for biological experiments in cell-free systems (Esterbauer et al. 1992).

Experiments in vitro, therefore, seem to indicate that $\mathrm{Cu}$ is a pro-oxidant and is involved in atherogenesis. These observations appear to be supported by epidemi- 


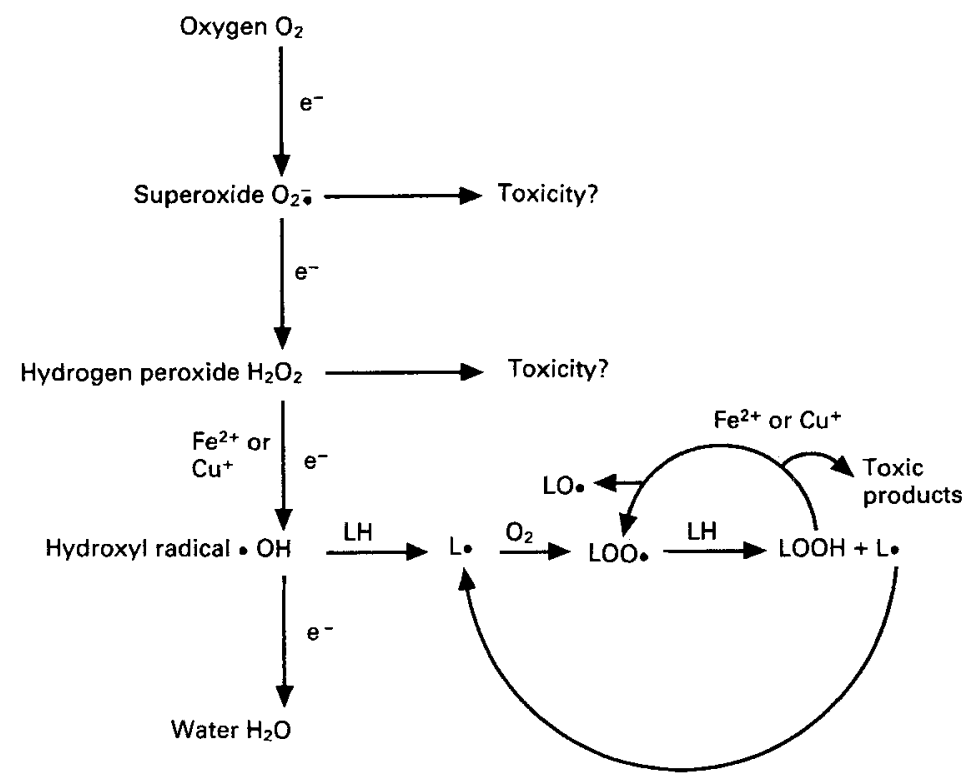

Fig. 1. Major reactive oxygen species in biological systems. LH, lipid; L•, lipid radical, LOO• lipid peroxyl radical; LO• lipid alkoxyl radical; $\mathrm{LOOH}$, lipid hydroperoxides.

ological data which have found increased serum $\mathrm{Cu}$ (Kok et al. 1988) or increased caeruloplasmin (EC 1.16.3.1), the major Cu-containing protein in serum (Reunanen et al. 1992), to be associated with increased risk of IHD in case-control studies. Serum $\mathrm{Cu}$, also, has been identified as a risk factor for IHD in a Finnish prospective study (Salonen et al. 1991a). The latter workers have concluded that high $\mathrm{Cu}$ status, as measured by elevated serum $\mathrm{Cu}$ concentration is an independent risk factor for IHD (Salonen et al. 1991a) and that there is evidence of a synergistic effect of $\mathrm{Cu}$ (a pro-oxidant), a low serum concentration of Se (a cofactor of an enzyme that scavenges free radicals) and LDL concentrations in atherogenesis (Salonen et al. 1991b).

A major defect in the interpretation of these studies arises in the assumption that serum $\mathrm{Cu}$ is indicative of high nutritional $\mathrm{Cu}$ status. In human populations, particularly ageing populations, serum $\mathrm{Cu}$ may reflect neither $\mathrm{Cu}$ intake nor organ $\mathrm{Cu}$ (Klevay, 1992; Arnaud, 1994; Milne \& Nielsen, 1994). This is because caeruloplasmin, which accounts for probably $95 \%$ or more of serum $\mathrm{Cu}$, is an acute-phase protein which rises sharply in inflammatory conditions. For example, DiSilvestro (1990) has shown that marginally-Cudeficient rats can respond to an inflammatory (turpentine) challenge by increasing caeruloplasmin activities ( $\mathrm{Cu}$ is required for this enzymic activity) to levels greater than in healthy $\mathrm{Cu}$-sufficient rats. Caeruloplasmin also acts as an antioxidant by oxidizing $\mathrm{Fe}^{2+}$ to $\mathrm{Fe}^{3+}$ (ferroxidase (EC 1.16.3.1) activity) without formation of ROS, by inhibiting lipid peroxidation and deoxyribose degradation stimulated by $\mathrm{Fe}$ or $\mathrm{Cu}$ ions, by slowly scavenging $\mathrm{H}_{2} \mathrm{O}_{2}$, superoxide and hydroxyl radical and by inhibiting carbonyl formation during inflammation (Krsek-Staples \& Webster, 1993). 


\section{COPPER AS AN ANTIOXIDANT}

The antioxidant nature of caeruloplasmin is in keeping with the antioxidant and anti-inflammatory effects of other Cu complexes in vivo (Sorenson, 1989) but is in sharp contrast to the pro-oxidant effects of $\mathrm{Cu}$ ions found in the test-tube. Perhaps it is not surprising that the effects of $\mathrm{Cu}$ are so different in vitro and in vivo, as the great bulk of $\mathrm{Cu}$ in the body is bound to storage and transport proteins in forms which are unable to act as pro-oxidants. Moreover, there is now accumulating evidence that adequate $\mathrm{Cu}$ is required to maintain antioxidant defences within the body, and $\mathrm{Cu}$ deficiency in animals can have pro-oxidant effects (for review, see Johnson et al. 1992). Some observations which suggest increased susceptibility to oxidant stress in vivo during $\mathrm{Cu}$ deficiency include: (a) increased rat mortality after hyperoxia (Jenkinson et al. 1984), (b) enhanced breath ethane of rats after intraperitoneal injection of carbon tetrachloride (Lawrence \& Jenkinson, 1987), (c) decreased body weight of mice after ozone treatment (Dubick et al. 1988), (d) increased breath ethane of rats in air and hyperoxia (Saari et al. 1990), (e) increased rat hepatic plasma membrane injury after intraperitoneal injection of carbon tetrachloride (DiSilvestro \& Medeiros, 1992), (f) exacerbated rat cardiomyopathy with focal collagen accumulation after aerobic exercise training (Davidson et al. 1993), (g) exaggerated respiratory membrane defects in rat lung after hyperbaric hyperoxia (Akers \& Saari, 1993). These studies are complemented by others where antioxidant supplementation during $\mathrm{Cu}$ deficiency in rats decreased putative measures of oxidant stress and include: (a) t-butylhydroquinone which ameliorated growth retardation, anaemia and cardiac hypertrophy (Johnson \& Saari, 1989), (b) dimethyl sulphoxide which inhibited cardiovascular, but not renal, changes (Saari et al. 1990), (c) vitamin E which decreased hepatic lipid peroxidation but not cardiac lipid peroxidation or mortality (Silverman et al. 1990), (d) coenzyme $\mathrm{Q}_{10}$ which decreased mortality and maintained the integrity of the heart but did not affect anaemia or cardiac enlargement (Lewis et al. 1993). Oxidant stress has also been demonstrated in cells and cellular fractions during $\mathrm{Cu}$ deficiency in vitro (for review, see Johnson et al. 1992).

Taken together these studies strongly suggest increased oxidant stress during $\mathrm{Cu}$ deficiency. Apart from caeruloplasmin, Cu deficiency is known to affect a number of other enzymes with antioxidant activities (Fig. 2). The alteration in $\mathrm{Cu}$ status of animals can result in changes in the activity of specific cuproenzymes, which can affect ROS production such as cytoplasmic, erythrocyte and extracelluar CuZn-superoxide dismutase (EC 1.15.1.1; CuZn-SOD), which facilitates the disproportionation of superoxide, and cytochrome $\mathrm{C}$ oxidase (EC 1.9.3.1; $\mathrm{CCO}$ ), which is involved in energy production via the electron chain. Decreased activity of the latter enzyme might encourage incomplete reduction of oxygen with the resulting enhancement of ROS production. Changes in $\mathrm{Cu}$ status can also affect many other enzymes not known to contain $\mathrm{Cu}$ (for review, see Prohaska, 1990). Those enzymes with antioxidant properties include Se-dependent glutathione peroxidase (EC 1.11.1.9; GSH-Px) and the ferroenzyme, catalase ( $E C$ 1.11.1.6). Furthermore, $\mathrm{Cu}$ deficiency results in lower hepatic mRNA concentrations of GSH-Px (Prohaska et al. 1992), and catalase (Lai et al. 1994a). These results suggest that $\mathrm{Cu}$ status has a regulatory effect on these enzymes at the molecular level affecting gene expression.

$\mathrm{Cu}$ deficiency may also affect Se metabolism independently of the antioxidant defence system, as the other known selenoenzyme, Type I iodothyronine-5-deiodinase (EC 3.8.1.4), is also lowered (Olin et al. 1994). The effects of Cu deficiency on the regulation 


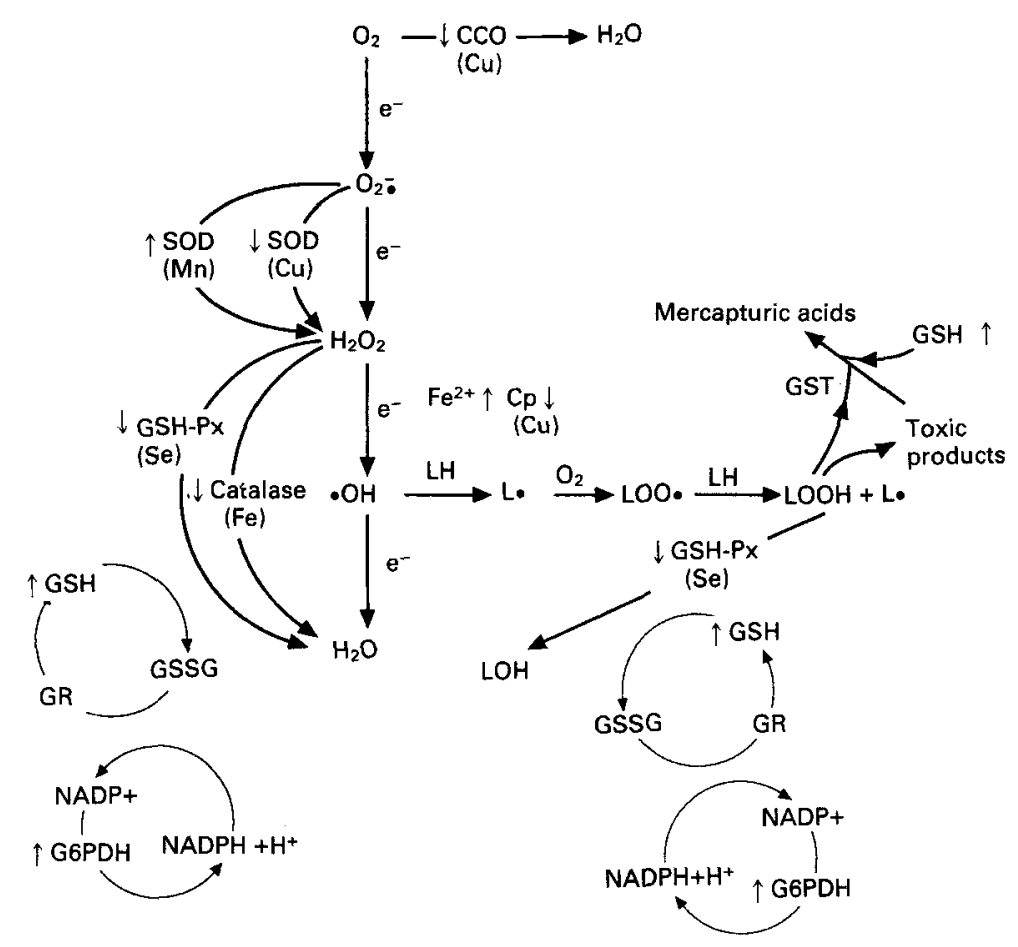

Fig. 2. Oxidant stress in copper deficiency. CCO, cytochrome $\mathrm{C}$ oxidase (EC 1.9.3.1); SOD, Mn- or CuZn-superoxide dismutase ( $E C$ 1.15.1.1); GSH-PX, glutathione peroxidase $(E C 1.11 .1 .9)$; catalase (EC 1.11.16); GSH, reduced glutathione; GSSG, oxidized glutathione; GR, glutathione reductase (EC 1.6.4.2); GST, glutathione-S-transferase ( $E C$ 2.5.1.18); G6PDH, glucose-6-phosphate dehydrogenase (EC 1.1.1.49) Cp, caeruloplasmin (EC 1.16.3.1); LH, lipid; L•, lipid radical, LOO•, lipid peroxyl radical, LO•, lipid alkoxyl radical; LOOH, lipid hydroperoxides; $\uparrow$, increased $\downarrow$, decreased activity or level.

of these enzymes are tissue specific with the brain generally being unaffected. Similarly, recent work indicates that CuZn-SOD activity, enzyme content and mRNA levels in the liver, and the activity and enzyme protein content of CuZn-SOD in the heart were decreased; in the brain dietary $\mathrm{Cu}$ deficiency had no affect (Lai et al. 1994b). In some studies (Lynch \& Strain, 1989) but not others (Lynch \& Strain, 1990) there is some compensatory increase in mitochondrial Mn-SOD (EC 1.15.1.1). Lai et al. (1994b) found that Mn-SOD activity, protein and mRNA levels increased in parallel (but were not fully compensatory) with decreases in CuZn-SOD in liver and heart. It appears, therefore, that the major antioxidant enzymes are, under conditions of oxidant stress imposed by dietary $\mathrm{Cu}$ deprivation, regulated at the molecular level and that different mechanisms (transcriptional, post-transcriptional or post-translational) may be involved in their regulation. Furthermore, apart from Mn-SOD, adaptations by inducement of the activities of these enzymes, which normally might occur under other conditions of oxidant stress, are prevented and/or repressed when there is an underlying dietary $\mathrm{Cu}$ deficiency.

Changes in the activities of other antioxidant enzymes during $\mathrm{Cu}$ deficiency are inconsistent. For example, glutathione-S-transferase (EC 2.5.1.18; GST) activities have been found to be increased (Lynch \& Strain, 1990), decreased (Prohaska, 1991) or 
unchanged (Arthur et al. 1987) in Cu deficiency under different dietary or physiological conditions. Glucose-6-phosphate dehydrogenase (EC 1.1.1.49; G6PDH) activity is generally found to be increased in the tissues of $\mathrm{Cu}$-deficient rats in our laboratory (Lynch \& Strain, 1989) and this may be an adaptive response since the enzyme is known to be subject to tissue-specific regulation by oxidant stress (Kletzien et al. 1994). G6PDH is the rate-determining enzyme in the pentose-phosphate pathway, regenerating NADPH from NADP for use by glutathione reductase $(E C$ 1.6.4.2) in reducing the oxidized (GSSG) form of glutathione to the reduced (GSH) form (White et al. 1994). Marked increases in hepatic GSH have also been found in $\mathrm{Cu}$ deficiency (Allen $\mathrm{et}$ al . 1988; Chao \& Allen, 1992), most probably as another adaptive response to increased oxidant stress.

\section{COPPER AND ATHEROSCLEROSIS}

Adaptive responses to the increased oxidant stress of $\mathrm{Cu}$ deficiency may help to explain the occurrence of the associated hypercholesterolaemia, first reported by Klevay (1973) over 20 years ago. Yount $e t$ al. (1990) found that $\mathrm{Cu}$ deficiency increases the activity of the rate-controlling enzyme of cholesterol biosynthesis, 3-hydroxy-3-methylglutarylcoenzyme A reductase (HMGCoA reductase, EC 1.1.1.34). This enzyme is subject to multiple regulatory mechanisms (Fig. 3). One such regulatory control is by thioldisulphide exchange (Cappel \& Gilbert, 1988). GSH is the principal cellular reductant for protein sulphydryls and increases in GSH can activate rat liver microsomal HMGCoA reductase by positive co-operativity in NADPH binding (Roitelman \& Shechter, 1981). Kim et al. (1992) prevented the rise in GSH in Cu-deficient rats by administering L-buthionine sulphoxide (BSO), a specific inhibitor of $\gamma$-glutamyl-cysteine synthetase ( $E C$ 6.3.2.2); this enzyme, which catalyses the production of the dipeptide $\gamma$-glutamyl-cysteine from glutamate and cysteine is rate-limiting for GSH synthesis. BSO was found to prevent the hypercholesterolaemia in the $\mathrm{Cu}$-deficient rats, suggesting that the increased GSH, probably resulting from increased oxidant stress, is responsible for the hypercholesterolaemia. Results also suggested that elevated hepatic GSH in $\mathrm{Cu}$ deficiency also either increased expression and/or decreased degradation of HMGCoA reductase, as dithiothreitol (DTT, a sulphydryl reductant) increased the activity of the enzyme ninefold in the Cu-deficient rats without BSO but only sixfold when BSO had been consumed. Interestingly G6PDH activity, another possible candidate for regulation by the GSH:GSSG value for hepatic tissue (Zeigler, 1985), is also increased in $\mathrm{Cu}$ deficiency (Lynch \& Strain, 1989).

$\mathrm{Cu}$ deficiency not only increases serum cholesterol but also increases the susceptibility of very-low-density lipoprotein (VLDL) and LDL to in vitro $\mathrm{Cu}$-induced oxidation (Rayssiguier et al. 1993). These workers also found increased thiobarbituric acid-reactive substances in heart and liver tissues from Cu-deficient rats while Nelson et al. (1992) found increased aortic lipid peroxides (malondialdehyde equivalents) in rats fed on $\mathrm{Cu}$-marginal and $\mathrm{Cu}$-deficient diets, the latter increase being associated with depressed aortic CuZn-SOD activity.

The contribution of hypercholesterolaemia and lipoprotein oxidizability to atherosclerotic-like changes in $\mathrm{Cu}$-deficient animals is controversial. Although arterial foam cells have been found in pigs deficient in $\mathrm{Cu}$ (Coulson \& Carnes, 1962), arterial disease in animals and in humans with the $\mathrm{Cu}$-deficiency genetic disorder, Menkes' disease, is 


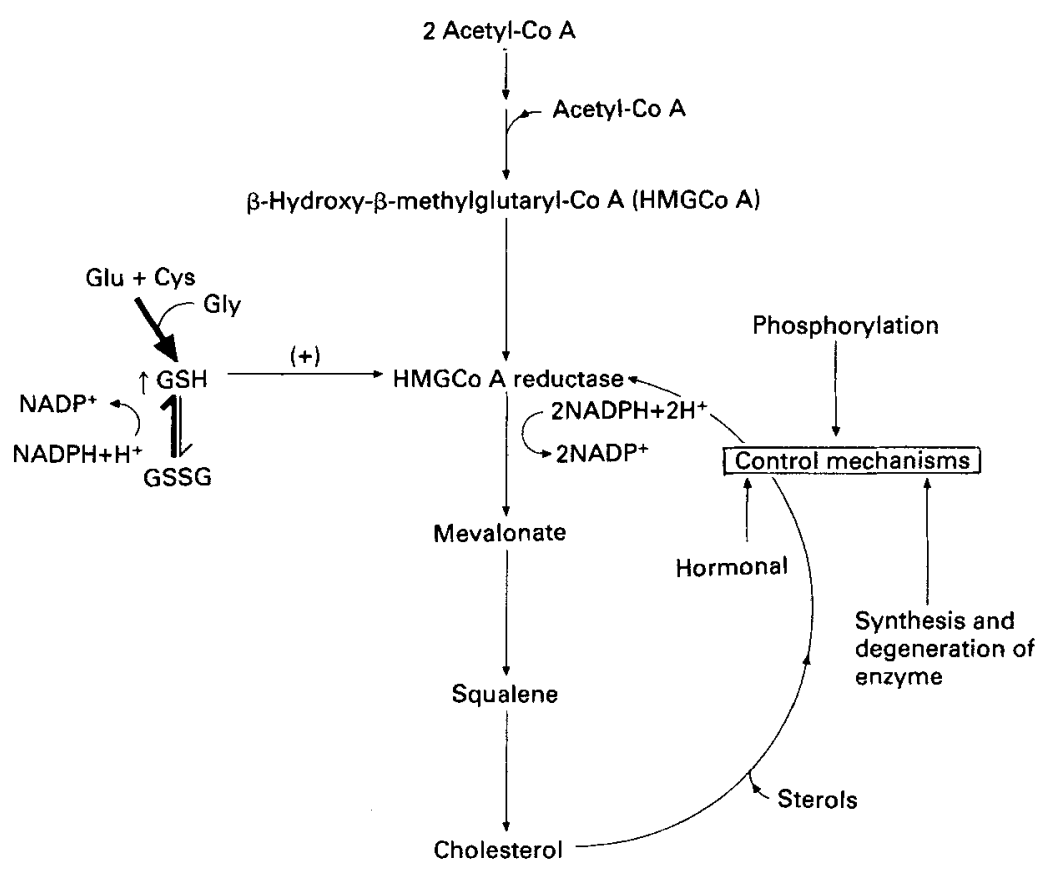

Fig. 3. Copper deficiency-induced hypercholesterolaemia. Glu, glutamate; Cys, cysteine; GSH, reduced glutathione; GSSG, oxidized glutathione; HMGCoA reductase, 3-hydroxy-3-methylglutaryl-coenzyme A reductase (EC 1.1.1.34); $\uparrow$ increased level; $(+)$, activation.

largely confined to the major arteries rather than the coronary arteries. In Menkes' disease the arterial abnormalities are elongation and dilation of major arteries, leading to rupture and haemorrhage and subintimal thickening with partial occlusion of major arteries (for review, see Danks, 1988). Changes in arterial walls in Menkes' disease, and in $\mathrm{Cu}$ deficiency in animals, principally involve large increases in soluble elastin and cross-linked mature fibrils (O'Dell, 1981), but the other two classes of connective tissue, collagen and ground substance, are also adversely affected by $\mathrm{Cu}$ deficiency in several species of animals (for review, see Klevay, 1990a). Klevay (1993) has recently reviewed the anatomical similarities between animals deficient in $\mathrm{Cu}$ and people with IHD and noted among the similarities: elastin degeneration, fibrosis, intramural haemorrhage, mucopolysaccharide increase, necrosis and smooth muscle proliferation. There are species differences in susceptibility to arterial disease in $\mathrm{Cu}$ deficiency, with pigs and poultry being particularly susceptible to aortic rupture and aneurysm while $\mathrm{Cu}$ deficiency in rats leads primarily to cardiomyopathy (Petering et al. 1986).

Abnormalities in the major arteries of animals with $\mathrm{Cu}$ deficiency are undoubtedly linked to lowered functional activity of the $\mathrm{Cu}$-containing enzyme, lysyl oxidase ( $E C$ 1.4.3.14) which oxidatively deaminates lysine or hydroxylysine residues in the biosynthesis of cross-links in collagen and elastin (Reiser et al. 1992). Nevertheless, the loss of structural integrity together with decreases in antioxidant enzyme activities, may also lead to increased oxidant stress in aortic tissue. There are few findings linking the oxidant 


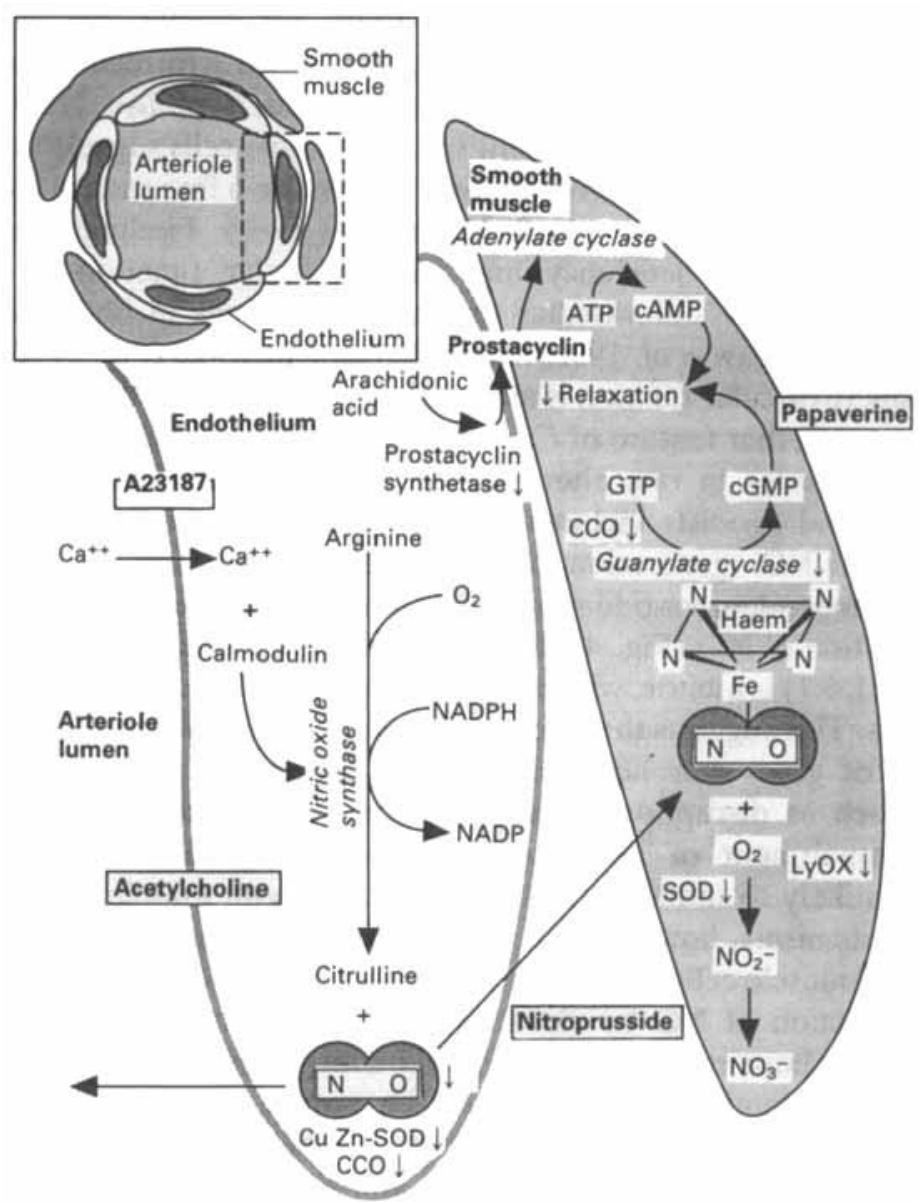

Fig. 4. Nitric oxide (NO) and vasodilation in copper deficiency. $\mathrm{CCO}$, cytochrome $\mathrm{C}$ oxidase (EC 1.9.3.1); SOD, CuZn-superoxide dismutase (EC 1.15.1.1); LyOX, lysyl oxidase ( $E C$ 1.4.3.14); cAMP, cyclic AMP; cGMP, cyclic GMP; A23187, a calcium ionophore; $\uparrow$, increased $\downarrow$, decreased activity or level (adapted from Anonymous, 1992).

stress, arising from low $\mathrm{Cu}$ status, with atherosclerosis in humans, but Dubick et al. (1987) found lower activity of CuZn-SOD in both aneurysmal and occluded aortic tissue from humans. Moreover, patients with chronic arterial disease had significantly lower erythrocyte SOD compared with healthy persons (Belch et al. 1989) and Kinsman et al. (1990) found a significant correlation between $\mathrm{Cu}$ in leucocytes and the degree of patency of the coronary arteries of non-smoking, non-hypercholesterolaemic men.

\section{COPPER AND ARTERIAL COMPLIANCE}

Changes in endothelial function occur early in vascular disease and can result in abnormal vasoconstriction, enhanced interactions of blood cells with the vessel wall, 
activation of coagulation mechanisms, and migration and proliferation of vascular smooth muscle cells (for review, see Lüscher, 1994). Fig. 4 highlights the involvement of one important endothelium-derived mediator, NO, which is formed from arginine by the action of a constitutive form of the enzyme, nitric oxide synthase. NO is a gas which is released into the lumen and into adjacent smooth muscle cells suggesting that it protects against both thrombosis and vasoconstriction. NO is also a free radical and can be swiftly inactivated by superoxide (Rubanyi \& Vanhoutte, 1986). Findings from a number of studies suggest that $\mathrm{Cu}$ deficiency may alter vascular function by modifying the interaction between NO and vascular smooth muscle cells in both the aorta and the microvasculature (Megaw et al. 1992; Saari, 1992a; Schuschke et al. 1992). The observed reduction in microvascular dilation is also of interest because of the possible relationship to hypertension, another feature of $\mathrm{Cu}$ deficiency (Klevay, 1987).

Mild $\mathrm{Cu}$ deficiencies in rats alter relaxation of the aorta and microvasculature in response to several agonists including acetylcholine and the $\mathrm{Ca}$ ionophore, $\mathrm{A} 23187$, which stimulate NO generation from arginine, and sodium nitroprusside, an endothelium-independent vasodilator that is thought to cause smooth muscle relaxation by direct formation of NO (Fig. 4). Response to papaverine, a non-specific phosphodiesterase (EC 3.1.4.1) inhibitor, which prevents the hydrolysis of cGMP, was not affected by low-Cu diets. This suggests that the vasodilatory capacity was not altered and together with the lack of gross morphological changes (Schuschke et al. 1992) suggests that mechanisms such as disruption of collagen and elastin integrity (via decreased lysyl oxidase) or impairment of mitochondrial energy production (via decreased CCO activity) are unlikely to influence the function of smooth muscle or endothelium. The most likely mechanisms, however, for the altered interactions in $\mathrm{Cu}$ deficiency between vascular smooth muscle cells and NO in large blood vessels and the microvasculature are enhanced destruction of $\mathrm{NO}$ by elevated superoxide (via decreased CuZn-SOD and $\mathrm{CCO}$ activities) or impaired interaction of $\mathrm{NO}$ with guanylate cyclase ( $E C$ 4.6.1.2; lung guanylate cyclase contains $\mathrm{Cu}$ and a haem-Fe group; Gerzer et al. 1981) leading to decreased cGTP for smooth muscle relaxation. Hypercholesterolaemia, which is known to affect endothelium-dependent relaxation and is associated with $\mathrm{Cu}$ deficiency, or decreased prostacyclin release, may also be involved. With respect to the latter, Nelson et al. (1992) found that there was decreased prostacyclin production by aortic rings from $\mathrm{Cu}$-deficient rats. Nevertheless, depressed endothelium-independent dilations suggested that there was some impairment of NO mediation.

\section{COPPER AND THROMBOSIS}

Continued synthesis of NO in vascular endothelium is required to maintain arterial blood vessels in an active state of vasodilation, but release of NO to the luminal surface also provides lubrication of the vascular wall and prevents platelets and leucocytes from adhering to the surface. Therefore, in both vasodilation and in providing a defence layer against the aggregation of activated platelets, NO may complement the actions of prostacyclin. If there is increased scavenging of NO by superoxide, a distinct possibility in Cu-deficient animals, then increased thrombotic activity might ensue. Also any impairment of prostacyclin production by arterial endothelium would give similar results. The observation by Nelson et al. (1992), that prostacyclin production by aortic rings taken from $\mathrm{Cu}$-deficient rats is lower than those from control animals, is 
particularly pertinent. Furthermore, decreases in aortic prostacyclin production in $\mathrm{Cu}$-deficient rats were associated with $\mathrm{CuZn-SOD}$ depression and increases in aortic lipid peroxides. These workers suggested that increased levels of hydroperoxides were responsible for inhibiting prostaglandin $\mathrm{H}$ synthase $(E C$ 1.14.99.1) the initial and rate-controlling step in the synthesis of prostaglandins and prostacyclin synthetase $(E C$ 5.3.99.4) which converts prostaglandin $\mathrm{H}$ to prostacyclin. Both enzymes (Lands et al. 1984), but especially prostacyclin synthetase (Moncada et al. 1976), are inhibited by lipid hydroperoxides. The mechanism of increased oxidant stress, therefore, may explain decreased prostacyclin production in $\mathrm{Cu}$ deficiency and also in vitamin E (Okuma et al. 1980) and Se (Schoene et al. 1986) deficiencies.

Interference by ROS with NO and/or prostacyclin inhibition of platelet aggregation could explain the massive occlusive atrial thromboses observed by Klevay (1985) in $\mathrm{Cu}$-deficient mice. Yet links between $\mathrm{Cu}$ status and thrombosis extend into coagulation pathways and are additional to effects postulated to arise from disturbances in oxidant-antioxidant balance. After platelet aggregation, the blood coagulation pathways encourage fusion of platelets and reinforce the stability of the evolving platelet plug. Platelets have procoagulant properties which can be classified into two groups: those which have collagen-induced coagulant activity and, thereby, activate the intrinsic pathway of blood coagulation, and those involving the formation of complexes between coagulation factors and platelet phospholipids. The two points in the cascade at which complexes between coagulation factors and platelet phospholipids occur involve participation of the factors VIII and V. Paradoxically these same clotting factors contain $\mathrm{Cu}$, and $\mathrm{Cu}$-deficient mice were found by Lynch \& Klevay (1992) to have lower factor V and VIII activities than those fed on a Cu-supplemented diet. These workers concluded that the haemostatic defect responsible for the observed thrombosis in $\mathrm{Cu}$-deficiency was not in the coagulation system. This seems a reasonable assumption as the bleeding disorders, haemophilia and van Willebrand's disease, are either caused by, or associated with, low factor VIII levels.

A further study by Lynch \& Klevay (1993) demonstrated a defect in the fibrinolytic system with a highly significant prolongation of euglobulin clot lysis time in $\mathrm{Cu}$-deficient mice. They also reported no significant differences in two important plasma coagulation inhibitors, anti-thrombin III and protein $\mathrm{C}$, although there was a trend $(P=0.08)$ towards lower plasma protein $\mathrm{C}$ activity in both male and female $\mathrm{Cu}$-deficient mice. Protein $\mathrm{C}$ is a key component in the regulation of haemostasis. It circulates in plasma as an inactive precursor but, after contact with thrombin that is bound to the thrombomodulin receptor on vascular endothelial cells, it is rapidly converted to activated protein C (APC). Once generated, APC acts as an anticoagulant by inactivating the two activated $\mathrm{Cu}$-dependent cofactors of the coagulation cascade, factors VIIIa and Va; therefore, a lowering of APC might be regarded as a homeostatic response which enables the $\mathrm{Cu}$-deficient animal to maintain a functional coagulation system. APC also plays an important role in the fibrinolytic pathway by decreasing the level of fast-acting plasminogen activator inhibitor-1 (PAI-1), thus effectively promoting fibrinolysis. APC resistance or decreased levels of APC would be expected to promote thrombosis and inhibit fibrinolysis. Recent findings suggest that APC resistance may occur in one-third (Dahlbäck et al. 1993) to over half (Griffin et al. 1993) the patients presenting with venous thrombosis and Bauer (1994) has indicated that revisions in current recommendations for screening for hereditary thrombotic disorders (as well as those prone to arterial thrombosis) may be 
necessary. Interestingly Dahlbäck \& Hildebrand (1994) have identified defects in factor $\mathrm{V}$ as the one responsible for hereditary APC resistance. Although factor $\mathrm{V}$ (when activated) promotes thrombosis by accelerating the activation of prothrombin to thrombin, it may also be required for anticoagulant (and fibrinolytic) activity. This seemingly paradoxical behaviour of a procoagulant having anticoagulant function is also demonstrated by thrombin, which is responsible for fibrin and clot formation yet when bound to thrombodulin converts protein C to APC. It is tempting to speculate that nutritional influences which decrease functional factor $\mathrm{V}$ levels may lead to thrombosis and, furthermore, that elevated levels of factor VII, an important risk factor for IHD, could be an adaptive response (for increasing factor $\mathrm{Xa}$ ) to low factor VIII levels owing to low $\mathrm{Cu}$ status in human populations.

\section{COPPER AND CARDIAC FUNCTION}

Feeding low- $\mathrm{Cu}$ diets to a number of animal species produces cardiac lesions and hypertrophy and often results in death by haemothorax or aneurysms. The cardiomyopathy of $\mathrm{Cu}$ deficiency is associated with concurrent hypertrophy in rats fed on low- $\mathrm{Cu}$ diets from weaning for 5-8 weeks while $\mathrm{Cu}$ deficiency-induced postweaning can produce cardiomyopathy without any apparent hypertrophy (Davidson et al. 1992). There is currently some debate as to the mechanisms which lead to cardiac hypertrophy in $\mathrm{Cu}$ deficiency (for review, see Medeiros et al. 1993). Hearts from Cu-deficient rats show a predominantly concentric pattern (Medeiros et al. 1991a) characterized by increased left ventricular mass:chamber volume, but with normal ventricular function (Strauer, 1979). Concentric cardiac hypertrophy is usually associated with increased systolic blood pressure and/or increased blood viscosity whereas eccentric hypertrophy (inappropriately low mass:chamber volume, resulting in left ventricular dysfunction) is more often observed in pregnancy, renal failure, obesity and anaemia. Jenkins \& Madeiros (1993) have shown that hearts in Cu-deficient rats fed on coconut oil with cholesterol have eccentric hypertrophy and ventricular dysfunction in contrast to the predominantly concentric nature of hearts in $\mathrm{Cu}$-deficient animals fed on maize oil. There is also some eccentric pattern usually shown in the enlarged heart of Cu deficiency, but cardiac hypertrophy can occur before anaemia and in the absence of hypertension (Medeiros et al. 1991a).

Two components, an enlarged mitochondrial area and myofibrillar enlargement appear to contribute to cardiac hypertrophy in $\mathrm{Cu}$ deficiency (Medeiros et al. 1991a). There are also additional ultrastructural and morphological changes in the left ventricle associated with Cu deficiency in both pigs (Medeiros et al. 1991b; Vadlamudi et al. 1993) and rats (Davidson et al. 1992). These include increases in type III:type I collagen (leading to greater compliance and elasticity), decreased collagen cross-linking, increased distances between the capillary lumen and myocyte mitochondria, and distortion of the basal laminae underlying the sarcolemma. Possible initiating factors leading to the cardiac hypertrophy and/or cardiomyopathy must include decreased activities of $\mathrm{Cu}$-dependent enzymes such as lysyl oxidase, CCO, CuZn-SOD and dopamine- $\beta$-hydroxylase ( $E C$ 1.14.17.1). The latter enzyme converts dopamine to noradrenaline and Seidel et al. (1991) have proposed that changes in the concentrations of noradrenaline and dopamine may contribute to the development of cardiac hypertrophy. Morphological observations indicate that dietary $\mathrm{Cu}$ deficiency results in structural 
damage to cardiac mitochrondria, which is associated with decreased mitochondrial respiration consistent with decreased $\mathrm{CCO}$ activity, but there is no difference in phosphorylation (amount of ADP phosphorylated per unit oxygen consumed) ability (Bode et al. 1992).

Undoubtedly increased oxidative stress must also be considered as a contributing factor in the cardiomyopathy. Decreased CuZn-SOD and caeruloplasmin may lower tissue antioxidant protection while increased leakage of ROS from the mitochondrial electron transport chain could be associated with decreased CCO activity. Dietary $\mathrm{Cu}$ deficiency reduces cardiac heart shock protein expression and this may decrease protection against oxidative or other stresses and contribute to the altered mitochondrial structure and function and the overall impairment of cardiac function known to accompany Cu deficiency (Matz et al. 1994).

It has been argued, with some justification, that the cardiac abnormalities seen in various animal models have more in common with the inherited cardiomyopathy, associated with CCO deficiency, in humans rather than IHD. Nevertheless there are many anatomical and electrophysiological similarities between animals deficient in $\mathrm{Cu}$ and humans with IHD (for review, see Klevay, 1993). Moreover electrocardiogram abnormalities have been reported in a male volunteer after 15 weeks on a diet supplying $0.8 \mathrm{mg} \mathrm{Cu} / \mathrm{d}$ (Klevay et al. 1984), while the study of Reiser et al. (1985) on twenty-four men with $\mathrm{Cu}$ intakes of $1 \mathrm{mg} / \mathrm{d}$ was terminated at 11 weeks after one man developed myocardial infarction ( 4 weeks), another tachycardia ( 7 weeks) and a third type II heart block (11 weeks). More recently three of twelve postmenopausal women, aged 49-75 years, on a low $\mathrm{Cu}(0.6 \mathrm{mg} \mathrm{Cu} / 8.4 \mathrm{MJ})$ diet exhibited changes in electrocardiograms during the $105 \mathrm{~d}$ depletion experiment and were supplemented early (Milne \& Nielsen, 1994). Turnland (1988), however, found no difference in cardiac function in eleven men after 6 weeks on diets containing $0.8 \mathrm{mg} \mathrm{Cu} / \mathrm{d}$. Hypercholesterolaemia, decreased glucose tolerance (historically one of the earliest recognized signs of $\mathrm{Cu}$ deficiency in animals), and abnormal blood pressure response to sustained hand grip have also been found in these $\mathrm{Cu}$-depletion experiments with human subjects.

\section{COPPER AND HUMAN NUTRITION}

Severe nutritional $\mathrm{Cu}$ deficiency has rarely been documented in human populations (Danks, 1988). Most diagnoses of $\mathrm{Cu}$ deficiency have been in elderly patients on parenteral nutrition and in young South American children with severe malnutrition and diarrhoea who had been premature babies. $\mathrm{Cu}$ deficiency, also, has been described in children undergoing chronic peritoneal dialysis and in patients given oral $\mathrm{Zn}$ supplements (for review, see Danks, 1988).

Although severe $\mathrm{Cu}$ deficiency in humans is not a public health problem, there is concern by some that a disparity may exist between putative $\mathrm{Cu}$ requirements and mean apparent intakes in Western populations, resulting in widespread mild, sub-clinical $\mathrm{Cu}$ deficiencies (Klevay, 1990b). Trying to evaluate the extent or consequences of a marginal $\mathrm{Cu}$ deficiency in humans, however, is problematic. First, there is currently no adequate way to diagnose mild $\mathrm{Cu}$ deficiency in human populations (Arnaud, 1994). Second, measurement of dietary intakes in populations is fraught with difficulty (Livingstone et al. 1990). Third, even if it were possible to measure Cu intakes accurately, functional $\mathrm{Cu}$ status of individuals will depend on interactions among $\mathrm{Cu}$ and a host of other dietary 
and lifestyle factors. Fourth, a chronic mild $\mathrm{Cu}$ deficiency may have markedly different outcomes from acute deficiency. With respect to the latter, Saari (1992b) has shown that differences in affected variables between chronic marginally $\mathrm{Cu}$-deficient rats and controls may be exaggerated, decreased or even reversed relative to differences between severely-deficient animals and controls. The need to examine balanced interactions within the whole diet rather than simply focusing on the amount of a particular trace element in a diet has been emphasized by Mertz (1993). Some examples of dietary interactions which might increase requirements for $\mathrm{Cu}$ in human diets are: sucrose or fructose (Schofield et al. 1990; O'Dell, 1993), animal proteins and S amino acids (Brown \& Strain, 1990; Lynch \& Strain, 1990; Fields et al. 1993; Kato et al. 1994), $\mathrm{Zn}$ and histidine (Wapnir et al. 1993). Beer (Klevay \& Moore, 1990), a peptide in mushrooms (Shimaoka et al. 1993) and possibly other antioxidants may decrease requirements. Interestingly fruit and vegetables, rich sources of some chain-breaking antioxidants, can contribute up to $30 \%$ of total $\mathrm{Cu}$ intake in some Western populations (Levander, 1990). Particularly rich food sources of $\mathrm{Cu}$ include offal, seafood, nuts, seeds, wholegrain cereals and legumes.

\section{SUMMARY}

$\mathrm{Cu}$ ions are pro-oxidants when added to biological material in vitro and excessive levels of $\mathrm{Cu}$ in the body, such as in Wilson's Disease (Yarze et al. 1992) promote oxidantrelated pathologies. In contrast there is now substantial evidence that an optimum level of $\mathrm{Cu}$ is required to maintain antioxidant defence and that $\mathrm{Cu}$ deficiency in animals increases oxidant stress. There are abundant mechanistic relationships linking $\mathrm{Cu}$ deficiency and processes associated with IHD, some of which do not directly involve oxidant damage. These mechanistic relationships, however, have mostly been demonstrated in animal models and more information is urgently required concerning possible chronic mild $\mathrm{Cu}$ deficiencies in human populations. A major hurdle to advances in this area is the lack of indices of $\mathrm{Cu}$ status which are sensitive enough to detect marginal $\mathrm{Cu}$ deficiency in humans. The question, therefore, of whether or not there is a role for mild $\mathrm{Cu}$ deficiency in the onset of chronic disease processes, including IHD, remains unanswered.

\section{REFERENCES}

Akers, T. K. \& Saari, J. T. (1993). Hyperbaric hyperoxia exaggerates respiratory membrane defects in the copper-deficient rat lung. Biological Trace Element Research 38, 149-163.

Allen, K. G. D., Arthur, J. R., Morrice, P. C., Nicol, F. \& Mills, C. F. (1988). Copper deficiency and tissue glutathione concentration in the rat. Proceedings of the Society of Experimental Biology and Medicine 187, 38-43.

Anonymous (1992). Pathways of nutritional biochemistry: nitric oxide and vasodilation. Journal of Nutritional Biochemistry 3, 437-438.

Arnaud, J. (1994). Copper. International Journal for Vitamin and Nutrition Research 63, 308-311.

Arthur, J. R., Morrice, P. C., Nicol, F., Beddows, S. E., Boyd, R., Hayes, J. D. \& Beckett, G. J. (1987). The effects of selenium and copper deficiencies on glutathione S-transferase and glutathione peroxidase in rat liver. Biochemical Journal 248, 539-544.

Bauer, K. A. (1994). Hypercoagulability - a new cofactor in the protein C anticoagulant pathway. New England Journal of Medicine 330, 566-567.

Belch, J. J. F., Chopra, M., Hutchinson, S., Stanick, R. D., Forbes, C. D. \& Smith, W. E. (1989). Free radical pathology in chronic arterial disease. Free Radical Biology and Medicine 6, 375-378. 
Bode, A. M., Miller, L. A., Faber, J. \& Saari, J. T. (1992). Mitochondrial respiration in heart, liver, and kidney of copper-deficient rats. Journal of Nutritional Biochemistry 3, 668-672.

Brown, J. C. W. \& Strain, J. J. (1990). Effect of dietary homocysteine on copper status in rats. Journal of Nutrition 120, 1068-1074.

Cappel, R. E. \& Gilbert, H. F. (1988). Thiol-disulfide exchange between 3-hydroxy-3-methylglutaryl CoA reductase and glutathione. Journal of Biological Chemistry 263, 12204-12212.

Chao, P. Y. \& Allen, K. G. D. (1992). Glutathione production in copper-deficient isolated rat hepatocytes. Free Radical Biology and Medicine 12, 145-150.

Cheeseman, K. H. \& Slater, T. F. (1993). An introduction to free radical biochemistry. British Medical Bulletin 49, 481-493.

Coulson, W. \& Carnes, W. W. H. (1962). Cardiovascular studies on copper deficient swine. XIII. The effect of chronic copper deficiency on the cardiovascular system of miniature pigs. Laboratory Investigation 11, 1316-1321.

Dahlbäck, B., Carosson, M. \& Svensson, P. J. (1993). Familial thrombophilia due to a previously unrecognised mechanism characterised by poor anticoagulant response to activated protein $\mathrm{C}$ : prediction of a cofactor to activated protein C. Proceedings of the National Academy of Sciences USA 90, 1004-1008.

Dahlbäck, B. \& Hildebrand, B. (1994). Inherited resistance to activated protein C is corrected by anticoagulant cofactor activity found to be a property of factor V. Proceedings of the National Academy of Sciences USA 91, 1396-1400.

Danks, D. M. (1988). Copper deficiency in humans. Annual Review of Nutrition 8, 235-257.

Davidson, J., Medeiros, D. M. \& Hamlin, R. L. (1992). Cardiac ultrastructural and electrophysiological abnormalities in postweanling copper-restricted and copper-repleted rats in the absence of hypertrophy. Journal of Nutrition 122, 1566-1575.

Davidson, J., Medeiros, D. M. Hamlin, R. L. \& Jenkins, J. E. (1993). Submaximal, aerobic exercise training exacerbates the cardiomyopathy of postweanling $\mathrm{Cu}$-depleted rats. Biological Trace Element Research 38 , 251-272.

DiSilvestro, R. A. (1990). Influence of dietary copper, copper injections and inflammation on rat serum caeruloplasmin activity levels. Nutrition Research 10, 355-358.

DiSilvestro, R. A. \& Medeiros, D. M. (1992). Low and marginal copper intake of postweanling rats: effects on copper status and resistance to carbon tetrachloride hepatotoxicity. Metabolism 41, 1122-1124.

Dubick, M. A., Hunter, G. C., Casey, S. M. \& Keen, C. L. (1987). Aortic ascorbic acid, trace elements and superoxide dismutase activity in human aneurysmal and occlusive disease. Proceedings of the Society for Experimental Biology and Medicine 184, 138-143.

Dubick, M. A., Zidenberg-Cherr, S., Rucker, R. B. \& Keen, C. L. (1988). Superoxide dismutase activity in lung from copper- and manganese-deficient mice exposed to ozone. Toxicology Letters 42, 149-154.

Esterbauer, H., Gebicki, J., Puhl, H. \& Jürgens, G. (1992). The role of lipid peroxidation and antioxidants in oxidative modification of LDL. Free Radical Biology and Medicine 13, 341-390.

Fields, M., Lewis, C. G. \& Lure, M. D. (1993). Copper deficiency in rats: the effect of dietary protein. Journal of the American College of Nutrition 12, 303-306.

Gerzer, R., Bohme, E., Hofmann, F. \& Schultz, G. (1981). Soluble guanylate cyclase purified from bovine lung contains heme and copper. FEBS Letters 132, 71-74.

Griffin, J. H., Evatt, B., Wideman, C. \& Fermandez, J. A. (1993). Anticoagulant protein C pathway defective in majority of thrombophilic patients. Blood 82, 1989-1993.

Halliwell, B. \& Chirico, S. (1993). Lipid peroxidation: its mechanism, measurement and significance. American Journal of Clinical Nutrition 57, Suppl., 715S-725S.

Jenkins, J. E. \& Medeiros, D. M. (1993). Diets containing corn oil, coconut oil and cholesterol alter ventricular hypertrophy, dilatation and function of hearts of rats fed copper-deficient diets. Journal of Nutrition 123, 1150-1160.

Jenkinson, S. G., Lawrence, R. A., Grafton, W. D., Gregory, P. E. \& McKinney, M. A. (1984). Enhanced pulmonary toxicity in copper-deficient rats exposed to hyperoxia. Fundamentals of Applied Toxicology 4, 170-177.

Johnson, M. A., Fischer, J. G. \& Kays, S. E. (1992). Is copper an antioxidant nutrient? Critical Reviews in Food Science and Nutrition 32, 1-31.

Johnson, W. T. \& Saari, J. T. (1989). Dietary supplementation with t-butylhydroquinone reduces cardiac hypertrophy and anemia associated with copper deficiency in rats. Nutrition Research 9, 1355-1362.

Kato, N., Saari, J. T. \& Schelkoph, G. M. (1994). Cystine feeding enhances defects of dietary copper deficiency by a mechanism not involving oxidative stress. Journal of Nutritional Biochemistry 5, 99-105. 
Kim, S., Chao, P. Y. \& Allen, K. G. D. (1992). Inhibition of elevated hepatic glutathione abolishes copper deficiency cholesterolemia. FASEB Journal 6, 2467-2471.

Kinsman, G. D., Howard, A. N., Stone, D. L. \& Mullins, P. A. (1990). Studies in copper status and atherosclerosis. Biochemical Society Transactions 18, 1186-1188.

Kletzien, R. F., Harris, P. K. W. \& Foellmi, L. A. (1994). Glucose-6-phosphate dehydrogenase: a 'housekeeping' enzyme subject to tissue-specific regulation by hormones, nutrients, and oxidant stress. FASEB Journal 8, 174-181.

Klevay, L. M. (1973). Hypercholesterolemia in rats produced by an increase in the ratio of zinc to copper ingested. American Journal of Clinical Nutrition 26, 1060-1068.

Klevay, L. M. (1985). Atrial thrombosis, abnormal electrogram and sudden death in mice due to copper deficiency. Atherosclerosis 54, 213-224.

Klevay, L. M. (1987). Hypertension in rats due to copper deficiency. Nutrition Reports International 35, 999-1005.

Klevay, L. M. (1990a). Ischemic heart disease as copper deficiency. In Copper Bioavailability and Metabolism, pp. 197-208 [C. Kies, editor]. New York: Plenum Publishing Corporation.

Klevay, L. M. (1990b). Ischemic heart disease: towards a unified theory. In Role of Copper in Lipid Metabolism, pp. 233-267 [K. Y. Lei and T. P. Carr, editors]. Boca Raton: CRC Press.

Klevay, L. M. (1992). Re: 'Serum copper and the risk of acute myocardial infarction: a prospective population study in men in eastern Finland' (Letter). American Journal of Epidemiology 135, 832-833.

Klevay, L. M. (1993). Ischaemic heart disease: nutrition or pharmacotherapy. Journal of Trace Elements and Electrolytes in Health and Disease 7, 63-69.

Klevay, L. M., Inman, L., Johnson, L. K., Lawler, H., Mahalko, J. R., Milne, D. B., Lukaski, H. C., Bolonchick, W. \& Sendstead, H. H. (1984). Increased cholesterol in plasma in a young man during experimental copper depletion. Metabolism 33, 1112-1118.

Klevay, L. M. \& Moore, R. J. (1990). Beer mitigates some effects of copper deficiency in rats. American Journal of Clinical Nutrition 51, 869-872.

Kok, F. J., Van Duiyn, M., Hofman, A., Van der Voet, G. B., De Wolff, F. A., Paays, C. H. Ch. \& Valkenburg, H. A. (1988). Serum copper and zinc and the risk of death from cancer and cardiovascular disease. American Journal of Epidemiology 128, 352-359.

Krsek-Staples, J. A. \& Webester, R. O. (1993). Ceruloplasmin inhibits carbonyl formation in endogenous cell proteins. Free Radical Biology and Medicine 14, 115-125.

Lai, C.-C., Huang, W.-H., Askari, A., Klevay, L. M. \& Chiu, T. H. (1994a). Regulation of catalase (CAT) and glutathione peroxidase (GSPX) in copper-deficient rat liver and heart. FASEB Journal 8, A677.

Lai, C.-C., Huang, W.-H., Askari, A., Wang, Y., Sarvazyan, N., Klevay, L. M. \& Chiu, T. H. (1994b). Differential regulation of superoxide dismutase in copper-deficient rat organs. Free Radical Biology and Medicine 16, 613-620.

Lands, W. E. M., Kulmaez, R. J. \& Marshall, P. J. (1984). Lipid peroxide actions in the regulation of prostaglandin synthesis. In Free Radicals in Biology, vol. 4, pp. 39-63 [W. A. Pryor, editor]. New York: Academic Press.

Lawrence, R. A. \& Jenkinson, S. G. (1987). Effects of copper deficiency on carbon tetrachloride-induced lipid peroxidation. Journal of Laboratory and Clinical Medicine 109, 134-140.

Levander, O. A. (1990). Fruit and vegetable contribution to dietary mineral intake in human health and disease. Horticultural Science 25, 1486-1488.

Lewis, C. G., Fields, M., Burns, W. A. \& Lure, M. D. (1993). Effect of coenzyme $Q_{10}$ supplementation on cardiac hypertrophy of male rats consuming a high-fructose, low-copper diet. Biological Trace Element Research 37, 137-149.

Livingstone, M. B. E., Prentice, A. M., Strain, J. J., Coward, W. A., Black, A. E., Barker, M. E., McKenna, P. G. \& Whitehead, R. G. (1990). Accuracy of weighed dietary records in studies of diet and health. British Medical Journal 300, 708-712.

Lüscher, T. F. (1994). The endothelium and cardiovascular disease - a complex relation. New England Journal of Medicine 330, 1081-1083.

Lynch, S. M. \& Frei, B. (1993). Mechanisms of copper- and iron-dependent oxidative modification of human low density lipoprotein. Journal of Lipid Research 34, 1745-1753.

Lynch, S. M. \& Klevay, L. M. (1992). Effect of a dietary copper deficiency on plasma coagulation factor activities in male and female mice. Journal of Nutritional Biochemistry 3, 387-391.

Lynch, S. M. \& Klevay, L. M. (1993). Effect of a dietary copper deficiency on plasma fibrinolytic activity in male and female mice. Nutrition Research 13, 913-922. 
Lynch, S. M. \& Strain, J. J. (1989). Effects of copper deficiency on hepatic and cardiac antioxidant enzyme activities in lactose- and sucrose-fed rats. British Journal of Nutrition 61, 345-354.

Lynch, S. M. \& Strain, J. J. (1990). Effects of skimmed milk powders, whey or casein on tissue trace element status and antioxidant enzyme activities in rats fed control and copper-deficient diets. Nutrition Research 10, $449-460$.

Matz, J. M., Blake, M. J., Saari, J. T. \& Bode, A. M. (1994). Dietary copper deficiency reduces heat shock protein expression in cardiovascular tissues. FASEB Journal 8, 97-102.

Medeiros, D. M., Bagby, D., Ovecka, G. \& McCormick, R. (1991a). Myofibrillar, mitochondrial and valvular morphological alterations in cardiac hypertrophy among copper deficient rats. Journal of Nutrition 121, 815-825.

Medeiros, D. M., Davidson, J. \& Jenkins, J. E. (1993). A unified perspective on copper deficiency and cardiomyopathy. Proceedings of the Society of Experimental Biology and Medicine 203, 262-273.

Medeiros, D. M., Failla, M. L., Schoenemann, H. M. \& Ovecka, G. D. (1991b). Morphometric analysis of myocardium from copper-deficient pigs. Nutrition Research 11, 1439-1450.

Megaw, D. P., Allen, J. M. \& Strain, J. J. (1992). Copper deficiency and endothelium dependent relaxations of rat aorta in vitro. Irish Journal of Medical Science 161, 646-647.

Mertz, W. (1993). Essential trace metals: new definitions based on new paradigms. Nutrition Reviews 51, 287-295.

Milne, D. M. \& Nielsen, F. H. (1994). Effects of a short-term copper deprivation on postmenopausal women. FASEB Journal 8, A820.

Moncada, S., Gryglewski, R. J., Bunting, S. \& Vane, J. R. (1976). Lipid peroxide inhibits enzyme in blood vessel microsomes that generates from prostaglandin endoperoxides substance (prostaglandin-X) which prevents platelet aggregation. Prostaglandins 12, 715-738.

Nelson, S. K., Huang, C.-J., Mathias, M. M. \& Allen, K. G. D. (1992). Copper-marginal and copper-deficient diets decrease aortic prostacyclin production and copper-dependent superoxide dismutase activities and increase aortic lipid peroxidation in rats. Journal of Nutrition 122, 2101-2108.

O'Dell, B. L. (1981). Roles for iron and copper in connective tissue biosynthesis. Philosophical Transactions of the Royal Society of London Series B 294, 91-104.

O'Dell, B. L. (1993). Fructose and mineral metabolism. American Journal of Clinical Nutrition 58, Suppl., 771S-778s.

Okuma, M., Takayama, H. \& Uchino, H. (1980). Generation of prostacyclin-like substance and lipid peroxidation in vitamin E-deficient rats. Prostaglandins 19, 527-536.

Olin, K. L., Walter, R. M. \& Keen, C. L. (1994). Copper deficiency affects selenoglutathione peroxidase and selenodeiodinase activities and antioxidant defense in weanling rats. American Journal of Clinical Nutrition $59,654-658$.

Petering, H. G., Murthy, L., Stemmer, K. L., Finelli, V. N. \& Menden, E. E. (1986). Effects of copper deficiency on the cardiovascular system of the rat: the role of dietary sucrose and excessive zinc. Biological Trace Element Research 9, 251-270.

Prohaska, J. (1990). Biochemical changes in copper deficiency. Journal of Nutritional Biochemistry 1, 452-461.

Prohaska, J. R. (1991). Changes in $\mathrm{Cu}, \mathrm{Zn}$-superoxide dismutase, cytochrome $\mathrm{C}$ oxidase, glutathione peroxidase and glutathione transferase activities in copper-deficient mice and rats. Journal of Nutrition 121, 353-363.

Prohaska, J. R., Sunde, R. A. \& Zinn, K. R. (1992). Livers from copper-deficient rats have lower glutathione peroxidase activity and mRNA levels but normal liver selenium levels. Journal of Nutritional Biochemistry 3, 429-436.

Rayssiguier, Y., Gueux, E., Bussiere, L. \& Mazur, A. (1993). Copper deficiency increases the susceptibility of lipoproteins and tissues to peroxidation in rats. Journal of Nutrition 23, 1343-1348.

Reiser, K., McCormick, R. J. \& Rucker, R. B. (1992). Enzymatic and nonenzymatic cross-linking of collagen and elastin. FASEB Journal 6, 2439-2449.

Reiser, S., Smith, J. C., Mertz, W., Hollbrook, J. T., Schofield, D. J., Powell, A. S., Camfield, W. K. \& Conary, J. J. (1985). Indices of copper status in humans consuming a typical American diet containing either fructose or starch. American Journal of Clinical Nutrition 42, 242-251.

Reunanen, A., Knekt, P. \& Aaran, R.-K. (1992). Serum ceruloplasmin level and the risk of myocardial infarction and stroke. American Journal of Epidemiology 136, 1082-1090.

Roitelman, J. \& Schechter, I. (1981). Regulation of rat liver 3-hydroxy-3-methylglutaryl coenzyme A reductase. Journal of Biological Chemistry 259, 870-877. 
Rubanyi, G. M. \& Vanhoutte, P. M. (1986). Superoxide anions and hyperoxia inactivate endothelium-derived relaxing factor. American Journal of Physiology 250, H822-H827.

Saari, J. T. (1992a). Dietary copper deficiency and endothelium-dependent relaxation of rat aorta. Proceedings of the Society of Experimental Biology and Medicine 200, 19-24.

Saari, J. T. (1992b). Influence of long-term marginal copper deficiency on trace element status and cardiovascular variables in rats. Journal of Trace Elements in Experimental Medicine 5, 205-214.

Saari, J. T., Dickerson, F. D. \& Habib, M. P. (1990). Ethane production in copper-deficient rats. Proceedings of the Society for Experimental Biology and Medicine 195, 30-33.

Saari, J. T., Reeves, P. G., Noordewier, B., Hall, C. B. \& Lukaski, H. C. (1990). Cardiovascular but not renal effects of copper deficiency are inhibited by dimethyl sulphoxide. Nutrition Research 10, 467-477.

Salonen, J. T., Salonen, R., Korpela, H., Suntioinen, S. \& Tuomileho, J. (1991a). Serum copper and the risks of acute myocardial infarction: a prospective population study in men in eastern Finland. American Journal of Epidemiology 134, 268-276.

Salonen, J. T., Salonen, R., Seppären, K., Kantola, M., Suntioinen, S. \& Korpela, H. (1991b). Interactions of serum copper, selenium, and low density lipoprotein cholesterol in atherogenesis. British Journal of Medicine 302, 756-760.

Schoene, N. W., Morris, V. C. \& Levander, O. A. (1986). Altered arachidonic acid metabolism in platelets and aortas from selenium-deficient rats. Nutrition Research 6, 75-83.

Schofield, D. J., Reiser, S., Fields, M., Steele, N. C., Smith, J. C., Darcey, S. \& Ono, K. (1990). Dietary copper, simple sugars, and metabolic changes in pigs. Journal of Nutritional Biochemistry 1, 362-368.

Schuschke. D. A., Reed, M. W. R., Saari, J. T. \& Miller, F. N. (1992). Copper deficiency alters vasodilation in the rat cremaster muscle microcirculation. Journal of Nutrition 122, 1547-1552.

Seidel, K. E., Failla, M. L. \& Rosebrough, R. W. (1991). Cardiac catecholamine metabolism in copperdeficient rats. Journal of Nutrition 121, 474-483.

Shimaoka, I. . Kodama, J., Nishino, K. \& Itokawa, Y. (1993). Purification of a copper binding peptide from the mushroom Grifola frondosa and its effect on copper absorption. Journal of Nutritional Biochemistry 4, 33-38.

Silverman, S., Fields, M. \& Lewis, C. (1990). The effect of vitamin E on lipid peroxidation in the copper-deficient rat. Journal of Nutritional Biochemistry 1, 98-101.

Sorenson, J. R. J. (1989). Copper complexes offer a physiological approach to treatment of chronic diseases. In Progress in Medical Chemistry, pp. 437-568 [G. P. Ellis and G. B. West, editors]. New York: Elsevier.

Steinberg, D., Parthasarathy, S., Carew, T. E., Khoo, J. C. \& Witztum, J. L. (1989). Beyond cholesterol. Modification of low-density lipoprotein that increases its atherogenicity. New England Journal of Medicine 320, 915-924.

Strain, J. J., Hannigan, B. M. \& McKenna, P. G. (1991). The pathophysiology of oxidant damage. Journal of Biomedical Sciences 2, 19-24.

Strauer, B.-E. (1979). Ventricular function and coronary hemodynamics in hypertensive heart disease. American Journal of Cardiology 44, 999-1006.

Turnland, J. R. (1988). Copper nutriture bioavailability and the influence of dietary factors. Journal of American Dietetic Association 42, 242-251.

Vadlamudi, R. K., McCormick, R. J., Medeiros, D. M., Vossoughi, J. \& Failla, M. L. (1993). Copper deficiency alters collagen types and covalent cross-linking in swine myocardium and cardiac valves. American Journal of Physiology 264, H2154-H2161.

Wapnir, R. A., Devas, G. \& Solars, C. V. (1993). Inhibition of intestinal copper absorption by divalent cations and low-molecular-weight ligands in the rat. Biological Trace Element Research 36, 291-305.

White, A. C., Thannickal, V. J. \& Fanburg, B. L. (1994). Glutathione deficiency in human disease. Journal of Nutritional Biochemistry 5, 218-226.

Yarze, J. C., Martin, P., Munoz, S. J. \& Friedman, L. S. (1992). Wilson's disease: current status. American Journal of Medicine 92, 643-654.

Yount, N. Y., McNamara, D. J., Al-Othman, A. A. \& Lei, K. Y. (1990). The effect of copper deficiency on rat hepatic 3-hydroxy-3-methylglutaryl co-enzyme A reductase activity. Journal of Nutritional Biochemistry $\mathbf{1}$, 27-33.

Ziegler, D. M. (1985). Role of reversible oxidation-reduction of enzyme thiols - disulfides in metabolic regulation. Annual Review of Biochemistry 54, 305-329.

\section{Printed in Great Britain}

